\title{
Gastrointestinal Manifestations of Marfan Syndrome
}

Dr N Inayet, Dr J O Hayat, Dr A P Poullis, Dr M Tome, Dr A Child

St George's Hospital, London

Sources: Medline, PubMed, Google Scholar

Declarations: None identified

Keywords: Marfan; connective tissue disease; irritable bowel syndrome; hernia

\begin{abstract}
Symptoms attributed to the gastrointestinal manifestations of multisystem disorders play an important role in the long-term management of these conditions. Gastrointestinal complications of a variety of connective tissue disorders have been studied and there is an increased interest in the incidence and prevalence of these symptoms. Descriptions of the occurrence of gastrointestinal complications in Marfan syndrome have appeared infrequently in the medical literature. In this review article we focus on both structural and functional gastrointestinal pathology that may occur in patients with Marfan syndrome.
\end{abstract}

\section{Introduction}

Marfan syndrome is a spectrum of heritable disorders of connective tissue with a high degree of clinical variability[1]. It has an autosomal dominant mode of transmission mainly affecting the connective tissue protein fibrillin[2].The defect itself has been isolated to the FBN1 gene on chromosome 15, which codes for the connective tissue protein fibrillin[3].

Antonin Bernard Jean Marfan, a professor of paediatrics in Paris, presented what is thought to be the first description of Marfan syndrome at a meeting in 1896 where he presented the case of a 5-yearold child with disproportionately long limbs[4].

The most serious and common complications of Marfan syndrome are usually cardiovascular, skeletal, pulmonary and ocular. Aortic root dilatation and dissection[5] are perhaps the most serious manifestations whereas skeletal deformities[6] including thoracolumbar scoliosis, thoracic lordosis, and pectus excavatum can lead to pulmonary problems[7] if left untreated. In addition, ocular problems such as superior dislocation of the lens, retinal detachment, myopia, glaucoma and cataracts and are common findings and can lead to blindness if remain unrecognized[8]-[10].

Gastrointestinal symptoms and complications have been reported in a variety of connective tissue disorders[11]-[13] such as Ehlers-Danlos syndrome[14] and in this review, we will consider the gastrointestinal manifestations of Marfan syndrome. 


\section{Pathophysiology}

A variety of molecules in the extracellular matrix including collagen, elastin, hyaluronic acid and fibrillin have been studied with Sakai et al identifying fibrillin, a 350-kDa glycoprotein, by using monoclonal antibodies raised against myofibrils[15]. Later studies using immunofluorescence to construct genetic exclusion maps localised the defect to FBN1 locus of the fibrillin gene on chromosome 15(bands q15-q23)[16], [17].Point mutations in the fibrillin gene cause production of defective fibrillin. These point mutations affect cysteine residues within the microfibril causing abnormal protein folding due to alteration of bonds between cysteine residues[18].

FBN1 gene mutations either reduce the amount of fibrillin-1 produced by the cell, alter the structure and stability of fibrillin-1, or impair the transport of fibrillin-1 out of the cell leading to a severe reduction in the amount of fibrillin-1 available to form microfibrils[19]. Excess TGF- $\beta$ growth factors are activated as a result of microfibril deficiency leading to instability of tissues and the signs and symptoms of Marfan syndrome[20], [21].

\section{Epidemiology}

The exact incidence of Marfan syndrome has been difficult to determine because the Fibrillin gene mutation is pleiotropic in nature. Hence, a diverse range of phenotypic features are derived from a single gene mutation which may mimic other diseases. The estimated incidence of Marfan syndrome ranges from 1 in 3300 to $2-3$ in 10,000 persons without any particular racial or gender predominance[5], [22], [23],[24].

\section{Diagnosis}

The diagnosis of Marfan syndrome is based on family history, the presence of certain clinical features such as aortic root dilatation and ectopia lentis as well as genetic testing for FBN1[1]. The revised Ghent criteria for diagnosing Marfan syndrome were published in 2010[25], [26].

\section{Ghent criteria}

The revised Ghent criteria for diagnosing Marfan syndrome puts emphasis on cardiovascular (aortic root dilatation), ocular (ectopia lentis), gene tests, family history and skeletal abnormalities[25]. It is based on the following seven rules.

In the absence of family history:

1.Aortic Root Dilatation Z score $\geq 2$ AND Ectopia Lentis = Marfan syndrome

2.Aortic Root Dilatation Z score $\geq 2$ AND FBN1 = Marfan syndrome

3.Aortic Root Dilatation Z score $\geq 2$ AND Systemic Score $\geq 7 \mathrm{pts}=$ Marfan syndrome

4. Ectopia lentis AND FBN1 with known Aortic Root Dilatation = Marfan syndrome

In the presence of family history:

5.Ectopia lentis AND Family History of Marfan syndrome (as defined above) = Marfan syndrome 
6.A systemic score $\geq 7$ points AND Family History of Marfan syndrome (as defined above) = Marfan syndrome

7.Aortic Root Dilatation Z score $\geq 2$ above 20 yrs. old, $\geq 3$ below 20 yrs. old) + Family History of Marfan syndrome (as defined above) = Marfan syndrome

\section{Gastrointestinal manifestations}

The gastrointestinal manifestations in connective tissue disorders can be broadly classified into structural complications such as visceral herniation, volvulus and diverticulosis; and functional or motility disorders with symptoms similar to the symptoms seen in irritable bowel syndrome. There has been very limited research in this area and much of the information comes from case reports and case series.

\section{Anatomical/Structural complications}

In 1984 Suster et al, described the case of a young woman with diverticulosis coli, involving the whole colon in the presence of Marfan syndrome. They noted a thinning of the wall with an absence of the muscularis propria and non-specific inflammation. They also commented that previously reported cases of gastrointestinal complications in Marfan syndrome such as inguinal and diaphragmatic herniae and perforation of appendix appeared to share a defect of muscle fibres found in their patient suggesting a possible causal relationship[27].

A case report in 1998 described multiple gastrointestinal complications in a person with Marfan syndrome namely diphragmatic hernia, inguinal herniae, diverticulosis coli and Zenker's diverticulum[28].

In 2007 a report described para-oesophageal hernia, which usually presents in the elderly, in a young man with Marfan syndrome[29].

More recently was described the simultaneous surgical repair of an ascending aortic aneurysm and a type IV hiatal hernia in a 35-year-old man with Marfan syndrome[30].

Another case report described a 25-year-old woman who presented with acute abdominal pain for 1 day. The imaging features revealed complex diaphragmatic hiatus hernia with symptomatic paraoesophageal hernia and organo-axial gastric volvulus[31].

A rare case of acute abdominal pain due to torsion of wandering spleen in a patient with Marfan Syndrome, valvular heart disease, and vertebral anomalies was reported in 2013[32].

The consideration of Marfan syndrome in young patients presenting with gastrointestinal symptoms was highlighted in the following case report by Inayat et al. They presented the case of a 31-year-old male, not known to have Marfan syndrome, who presented with acute abdominal pain and was diagnosed with sigmoid volvulus requiring decompression. His preoperative workup, including an echocardiography revealed aortic root dilatation which led to genetic testing confirming the diagnosis of Marfan syndrome[33].

Another case report describing an acute presentation of sigmoid volvulus in a 65 year old male details clinical features suggestive of Marfan syndrome also points to a causal relationship, however genetic testing was not mentioned in this case report[34].

A retrospective case-control study analysing computed tomography or magnetic resonance studies of 69 patients with Marfan syndrome against an age- and sex-matched cohort of control subjects showed 
that renal cysts and hepatic cysts in Marfan syndrome occurred more frequently, in increased number, and at an earlier age than controls. It also described a previously unrecognised increased prevalence of cholelithiasis in Marfan syndrome[35].

In addition to gastrointestinal manifestations in adult patients there are a few reports of gastrointestinal complications of Marfan syndrome in the paediatric population[36]-[39].

In summary, a variety of structural and visceral gastrointestinal manifestations have been observed and reported in Marfan syndrome affecting all age groups. Although the exact prevalence of gastrointestinal manifestations in Marfan syndrome is not known, the frequency of these reports suggests that these complications may be relatively uncommon as compared to more commonly seen cardiac, ophthalmic or skeletal manifestations but are important for clinicians to be aware of as failure to recognise them early can potentially lead to significant morbidity.

\section{Functional disorders}

Functional gastrointestinal symptoms in several connective tissue diseases have been widely reported[11], [40]-[44] but there is limited information on the prevalence of these symptoms in Marfan syndrome. An understanding of the prevalence and pathophysiology of these functional disorders may give insight into the cause of irritable bowel syndrome in patients without connective tissue disorders.

A questionnaire based study at St George's Hospital, University of London (which has a database of 3,500 patients with Marfan syndrome) involved 118 patients (56 men and 62 women) aged 18-88 years and compared them to two control groups. This showed that Marfan syndrome patients suffered more abdominal discomfort and irritable bowel syndrome symptoms as compared to the control groups. $40 \%$ of the Marfan syndrome group as compared to $15 \%$ of the control group reported symptoms, consisting of all types of Irritable bowel syndrome. Women with Marfan syndrome had higher rates of bloating and constipation than men[45].

\section{Conclusion}

Marfan syndrome is an inherited connective tissue multisystem disorder in which serious gastrointestinal manifestations are rare. However, a significant number of Marfan syndrome patients may have a number of structural and functional complications of the gastrointestinal tract which may affect them on a day to day basis.

There is a distinct lack of data save several case reports and questionnaire based studies on the gastrointestinal complications of Marfan syndrome and whilst further data is undoubtedly needed before any strong recommendations can be made, increased vigilance of the potential gastrointestinal complications would seem reasonable for those looking after patients with Marfan syndrome.

\section{References}

[1] H. C. Dietz, Marfan Syndrome. University of Washington, Seattle, 1993.

[2] D. P. Judge and H. C. Dietz, "Marfan's syndrome.," Lancet (London, England), vol. 366, no. 9501, pp. 1965-76, Dec. 2005.

[3] K. Kainulainen, L. Pulkkinen, A. Savolainen, I. Kaitila, and L. Peltonen, "Location on 
Chromosome 15 of the Gene Defect Causing Marfan Syndrome," N. Engl. J. Med., vol. 323, no. 14, pp. 935-939, Oct. 1990.

[4] A. Marfan, Un cas de déformation congénitale des quatre membres, plus prononcée aux extrémités, caractérisée par l'allongement des os avec un certain degré d'amincissement. Paris: Impr. Maretheux, 1896.

[5] N. M. Ammash, T. M. Sundt, and H. M. Connolly, "Marfan syndrome-diagnosis and management.," Curr. Probl. Cardiol., vol. 33, no. 1, pp. 7-39, Jan. 2008.

[6] H. I. Wilner and N. Finby, "Skeletal Manifestations in the Marfan Syndrome," JAMA, vol. 187, no. 7, pp. 490-495, Feb. 1964.

[7] J. R. Wood, D. Bellamy, A. H. Child, and K. M. Citron, "Pulmonary disease in patients with Marfan syndrome.," Thorax, vol. 39, no. 10, pp. 780-4, Oct. 1984.

[8] A. Y. Nemet, E. I. Assia, D. J. Apple, and I. S. Barequet, "Current concepts of ocular manifestations in Marfan syndrome.," Surv. Ophthalmol., vol. 51, no. 6, pp. 561-75, Nov. 2006.

[9] H. E. Cross and A. D. Jensen, "Ocular Manifestations in the Marfan Syndrome and Homocystinuria," Am. J. Ophthalmol., vol. 75, no. 3, pp. 405-420, Mar. 1973.

[10] R. A. Allen, B. R. Straatsma, L. Apt, and M. O. Hall, "Ocular manifestations of the Marfan syndrome.," Trans. Am. Acad. Ophthalmol. Otolaryngol., vol. 71, no. 1, pp. 18-38, 1967.

[11] A. Fikree et al., "Functional gastrointestinal disorders are associated with the joint hypermobility syndrome in secondary care: a case-control study," Neurogastroenterol. Motil., vol. 27, no. 4, pp. 569-579, 2015.

[12] J. P. Abonia et al., "High prevalence of eosinophilic esophagitis in patients with inherited connective tissue disorders.," J. Allergy Clin. Immunol., vol. 132, no. 2, pp. 378-86, Aug. 2013.

[13] G. Bolasco, C. Celletti, F. Camerota, I. Biviano, E. S. Corazziari, and D. Badiali, "PP-5 JOINT HYPERMOBILITY SYNDROME/EHLERS-DANLOS SYNDROME HYPERMOBILITY TYPE AND GASTROINTESTINAL SYMPTOMS," J. Pediatr. Gastroenterol. Nutr., vol. 61, no. 4, p. 522, Oct. 2015.

[14] P. H. Beighton, J. L. Murdoch, and T. Votteler, "Gastrointestinal complications of the EhlersDanlos syndrome.," Gut, vol. 10, no. 12, pp. 1004-8, 1969.

[15] L. Y. Sakai, D. R. Keene, and E. Engvall, "Fibrillin, a new 350-kD glycoprotein, is a component of extracellular microfibrils.," J. Cell Biol., vol. 103, no. 6 Pt 1, pp. 2499-509, Dec. 1986.

[16] D. W. Hollister, M. Godfrey, L. Y. Sakai, and R. E. Pyeritz, "Immunohistologic Abnormalities of the Microfibrillar-Fiber System in the Marfan Syndrome," N. Engl. J. Med., vol. 323, no. 3, pp. 152-159, Jul. 1990.

[17] C. L. Maslen, G. M. Corson, B. K. Maddox, R. W. Glanville, and L. Y. Sakai, "Partial sequence of a candidate gene for the Marfan syndrome," Nature, vol. 352, no. 6333, pp. 334-337, Jul. 1991.

[18] H. C. Dietz, J. M. Saraiva, R. E. Pyeritz, G. R. Cutting, and C. A. Francomano, "Clustering of fibrillin (FBN1) missense mutations in Marfan syndrome patients at cysteine residues in EGF-like domains," Hum. Mutat., vol. 1, no. 5, pp. 366-374, Jan. 1992.

[19] K. Tiedemann, B. Bätge, and D. P. Reinhardt, "Assembly of Microfibrils," 2013.

[20] J. A. Jones and J. S. Ikonomidis, "The pathogenesis of aortopathy in Marfan syndrome and related diseases.," Curr. Cardiol. Rep., vol. 12, no. 2, pp. 99-107, Mar. 2010. 
[21] M. Caputi, R. J. Kendzior, K. L. Beemon, and K. L. Beemon, "A nonsense mutation in the fibrillin1 gene of a Marfan syndrome patient induces NMD and disrupts an exonic splicing enhancer.," Genes Dev., vol. 16, no. 14, pp. 1754-9, Jul. 2002.

[22] H.-H. Chiu, M.-H. Wu, H.-C. Chen, F.-Y. Kao, and S.-K. Huang, "Epidemiological profile of Marfan syndrome in a general population: a national database study.," Mayo Clin. Proc., vol. 89, no. 1, pp. 34-42, Jan. 2014.

[23] J. L. Murdoch, B. A. Walker, B. L. Halpern, J. W. Kuzma, and V. A. McKusick, "Life Expectancy and Causes of Death in the Marfan Syndrome," N. Engl. J. Med., vol. 286, no. 15, pp. 804-808, Apr. 1972.

[24] M. Arslan-Kirchner et al., "Clinical utility gene card for: Marfan syndrome type 1 and related phenotypes [FBN1]," Eur. J. Hum. Genet., vol. 18, no. 9, 2010.

[25] B. L. Loeys et al., "The revised Ghent nosology for the Marfan syndrome.," J. Med. Genet., vol. 47, no. 7, pp. 476-85, Jul. 2010.

[26] Y. von Kodolitsch et al., "Perspectives on the revised Ghent criteria for the diagnosis of Marfan syndrome," Appl. Clin. Genet., vol. 8, p. 137, Jun. 2015.

[27] S. M. Suster, M. Ronnen, and J. J. Bubis, "Diverticulosis coli in association with Marfan's syndrome.," Arch. Intern. Med., vol. 144, no. 1, p. 203, Jan. 1984.

[28] R. Eliashar, J. Y. Sichel, A. Biron, and I. Dano, "Multiple gastrointestinal complications in Marfan syndrome.," Postgrad. Med. J., vol. 74, no. 874, pp. 495-7, Aug. 1998.

[29] R. N. Keswani, V. N. Prachand, and H. S. Te, "Paraesophageal hernia: a rare presentation of Marfan syndrome in adults," Gastrointest. Endosc., vol. 66, no. 5, pp. 1050-1052, Nov. 2007.

[30] J. Kothari, M. Hinduja, K. Baria, and H. Pandya, "Ascending aortic aneurysm and diaphragmatic hernia in a case of Marfan syndrome," Asian Cardiovasc. Thorac. Ann., vol. 25, no. 5, p. 21849231769369, Feb. 2017.

[31] S. Thakur, A. Jhobta, B. Sharma, A. Chauhan, and C. S. Thakur, "Unusual presentation of adult Marfan syndrome as a complex diaphragmatic hiatus hernia," Asian J. Surg., vol. 40, no. 4, pp. 313-316, Jul. 2017.

[32] L. Leci-Tahiri, A. Tahiri, R. Bajrami, and M. Maxhuni, "Acute abdomen due to torsion of the wandering spleen in a patient with Marfan Syndrome.," World J. Emerg. Surg., vol. 8, no. 1, p. 30, Aug. 2013.

[33] F. Inayat, A. Hurairah, and F. Shaikh, "Imaging, Endoscopic and Genetic Assessment of Marfan Syndrome Presenting with Sigmoid Volvulus: A Review," 2016.

[34] P. Junpaparp, M. Chayanupatkul, S. Buppajarntham, and P. Phowthongkum, "Sigmoid volvulus: is it related to Marfan syndrome?," Int. J. Colorectal Dis., vol. 29, no. 6, pp. 771-772, Jun. 2014.

[35] K. Chow, R. E. Pyeritz, and H. I. Litt, "Abdominal visceral findings in patients with Marfan syndrome.," Genet. Med., vol. 9, no. 4, pp. 208-12, Apr. 2007.

[36] S. K. Parida, V. M. Kriss, and B. D. Hall, "Hiatus/paraesophageal hernias in neonatal Marfan syndrome.," Am. J. Med. Genet., vol. 72, no. 2, pp. 156-8, Oct. 1997.

[37] P. Laumonerie, S. Mouttalib, T. Edouard, and P. Galinier, "Hernie de la fente de Larrey chez un nourrisson de trois mois atteint du syndrome de Marfan," Arch. Pédiatrie, vol. 22, no. 11, pp. 1151-1153, Nov. 2015. 
[38] T. F. Beck et al., "FBN1 contributing to familial congenital diaphragmatic hernia," Am. J. Med. Genet. Part A, vol. 167, no. 4, pp. 831-836, Apr. 2015.

[39] T. E. Herman, M. J. Siegel, A. Mathur, and A. Vachharajani, "Neonatal marfan syndrome with hiatus hernia and intrathoracic stomach," J. Perinatol., vol. 33, no. 8, pp. 652-653, Aug. 2013.

[40] J.-D. Zeitoun et al., "Functional digestive symptoms and quality of life in patients with EhlersDanlos syndromes: results of a national cohort study on 134 patients.," PLoS One, vol. 8, no. 11, p. e80321, 2013.

[41] A. B. Beckers et al., "Gastrointestinal disorders in joint hypermobility syndrome/Ehlers-Danlos syndrome hypermobility type: A review for the gastroenterologist," Neurogastroenterology and Motility, vol. 29, no. 8. 2017.

[42] A. D. Nelson et al., "Ehlers Danlos syndrome and gastrointestinal manifestations: A 20-year experience at Mayo Clinic," Neurogastroenterol. Motil., vol. 27, no. 11, pp. 1657-1666, 2015.

[43] X.-P. Tian and X. Zhang, "Gastrointestinal involvement in systemic lupus erythematosus: insight into pathogenesis, diagnosis and treatment.," World J. Gastroenterol., vol. 16, no. 24, pp. 2971-7, Jun. 2010.

[44] M. Castori, S. Morlino, G. Pascolini, C. Blundo, and P. Grammatico, "Gastrointestinal and nutritional issues in joint hypermobility syndrome/ehlers-danlos syndrome, hypermobility type," Am. J. Med. Genet. Part C Semin. Med. Genet., vol. 169, no. 1, pp. 54-75, Mar. 2015.

[45] B. Scoones and A. H. Child, "Gastrointestinal Symptoms in Patients with Marfan Syndrome," in Diagnosis and Management of Marfan Syndrome, London: Springer London, 2016, pp. 189200. 